Luiz Fernando Voss Chagas Lessa

\title{
A Internalização dos Tratados Internacionais de Direitos Humanos e a Constituição de 1988
}

DISSERTAÇÃo DE MESTRADO

DePARTAMENTO DE DiREITO

Programa de Pós-Graduação em Teoria do Estado e Direito Constitucional 

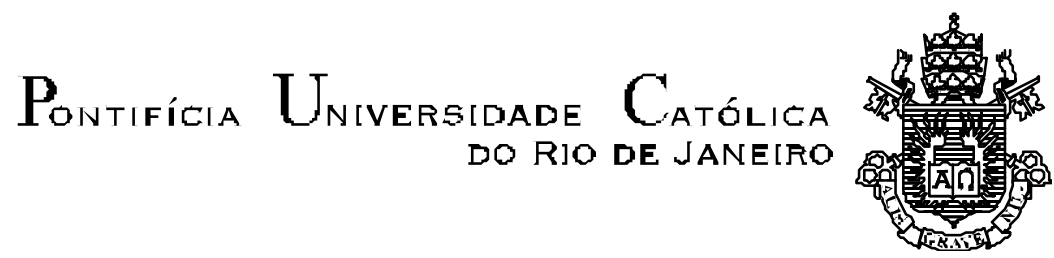

Luiz Fernando Voss Chagas Lessa

A Internalização dos Tratados Internacionais de Direitos
Humanos ante a Constituição de 1988.

Dissertação apresentada como requisito parcial para obtenção do título de Mestre pelo Programa de PósGraduação em Direito da PUC-Rio.

Orientadores: Nadia de Araujo Antonio Carlos de Souza Cavalcanti Maia 


\section{Pontifícia Universidade Católica $_{\text {a }}$ DO RIO DE JANEIRO}

Luiz Fernando Voss Chagas Lessa

\section{A Internalização dos Tratados Internacionais de Direitos Humanos e a Constituição de 1988.}

Dissertação apresentada como requisito parcial para obtenção do título de Mestre pelo Programa de PósGraduação em Direito da PUC-Rio. Aprovada pela Comissão Examinadora abaixo assinada.

Nadia de Araujo

Orientador

PUC-Rio

Antonio Carlos de Souza Cavalcanti Maia

PUC-Rio

Antonio Celso A. Pereira

UERJ

João Pontes Nogueira

Coordenador(a) Setorial do Centro de Ciências Sociais - PUC-Rio 
Todos os direitos reservados. É proibida a reprodução total ou parcial do trabalho sem autorização da universidade, do autor e dos orientadores.

\title{
Luiz Fernando Voss Chagas Lessa
}

Graduado em Direito pelas Faculdades Integradas Candido Mendes - Ipanema em 1992. É Professor de Direito Processual Civil da Pontifícia Universidade Católica do Rio de Janeiro (PUC-Rio) e Procurador da República no Estado do Rio de Janeiro com atuação na defesa dos direitos coletivos e difusos.

Ficha Catalográfica

\begin{abstract}
Lessa, Luiz Fernando Voss Chagas
A Internalização dos Tratados Internacionais de Direitos Humanos e a Constituição de 1988; orientadores: Nadia de Araujo e Antonio Carlos de Souza Cavalcanti Maia - Rio de Janeiro: PUC; Departamento de Direito, 2004.
\end{abstract}

$258 p$.

1. Dissertação (mestrado) - Pontifícia Universidade Católica do Rio de Janeiro, Departamento de Direito.

Incluí referências bibliográficas.

1. Direito - Dissertação. 2. A Internalização dos Tratados Internacionais de Direitos Humanos e a Constituição de 1988. 3. Direito Internacional. 4. Direito Constitucional. 5. Direitos Humanos. I. Lessa, Luiz Fernando Voss Chagas. II. Araujo, Nadia. III Maia, Antonio Carlos de Souza Cavalcanti. IV. Pontifícia Universidade Católica do Rio de Janeiro. Departamento de Direito. V. Título. 
À memória de minha mãe, Ingrid. Para meu pai, Luiz Fernando, e, especialmente, para minhas amadas e adoradas esposa e filha, Márcia e Ana Paula. 


\section{Agradecimentos}

Aos meus orientadores Nadia Araujo e Antonio Carlos de Souza Cavalcante Maia sem os quais este trabalho jamais teria se realizado.

À PUC-Rio e ao CAPES pelos auxílios recebidos.

Aos meus colegas de Ministério Público Federal, Paulo Thadeu Gomes da Silva, Daniel Sarmento, Samantha Chantal Dobrowolski, Paula Bajer Fernandes Martins da Costa, Luiza Cristina Fonseca Frischeinsen, André de Carvalho Ramos e Maurício Andreioulo, professores cujos escritos, preleções e opiniões são parte fundamental da presente dissertação.

Aos Professores de Direito da PUC, tanto da Graduação, como da Pós-Graduação, sempre dispostos a ensinar.

Aos colegas de mestrado, companheiros de uma bela jornada.

Aos funcionários da PUC sempre prontos a prestar sua inestimável ajuda. 


\section{Resumo}

Luiz Fernando Voss Chagas Lessa. A Internalização dos Tratados Internacionais de Direitos Humanos e a Constituição de 1988. Rio de Janeiro, 2004. 258 p. Dissertação de Mestrado - Departamento de Direito, Pontifícia Universidade Católica do Rio de Janeiro.

A Internalização dos Tratados Internacionais de Direitos Humanos e a Constituição de 1988. A partir da promulgação da Constituição da República de 1988 a doutrina brasileira vem tentado defender a tese de que os pactos internacionais de direitos humanos são incorporados de forma automática ao direito interno, bastando para tanto sua ratificação no plano internacional. Os mesmo autores defendem, ainda, o status de norma de direito fundamental destes pactos uma vez incorporados. Partindo dessas duas assertivas, a presente dissertação, rejeita o primeiro postulado para afirmar que o caráter de norma constitucional das normas internacionais internalizadas decorre antes de tudo de seu conteúdo e não da forma de sua internalização. Do mesmo modo, pugna o presente trabalho que a adoção do rito tradicional para a internalização de tratados internacionais que versem sobre os direitos humanos não significa outorgar ao Executivo uma carta branca para postergar a prática dos atos necessários para a sua incorporação. Ao final, defende a possibilidade da intervenção do Poder Judiciário para assegurar a proteção dos direitos individuais ameaçados ou lesados por tal omissão.

\section{Palavras-chave}

Direitos fundamentais; direitos humanos; tratados internacionais; internalização; promulgação; devido processo legislativo; mandado de injunção; mandado de segurança. 


\section{Abstract}

Luiz Fernando Voss Chagas Lessa. International Human Rights Treaties and the 1988 Constitution. Rio de Janeiro, 2004. 258 p. LLM Dissertation - Departamento de Direito, Pontifícia Universidade Católica do Rio de Janeiro.

The relationship between International Human Rights Law and municipal law in Brazil has taken a new turn with the adoption of a new Constitution in 1988. Human Rights lawyers and law teachers support the idea that the new Constitutional Charter allow for a monistic approach to the relationship between International Human Rights Law and municipal law. The present dissertation contends that even in the case of a Human Rights treaty the Brazilian Constitution demands an act destined to transform International Law in domestic law. Contrary to what these Human Rights advocates and theorists believe, the dualist theory allows, not only for the International Human Rights Law to be adopted in Brazil as material Constitutional Law, but for its prompt adoption after the entry in force of any human rights treaty ratified by Brazil. Also, this dissertation contends that in those cases that the delay in transforming International Law in municipal law harms individual rights, the Judiciary branch can offer a quick and effective response.

\section{Keywords}

Fundamental rights; human rights; international treaties; transformation; promulgation; substantial due process of law; legitimacy; writ of injunction; writ of mandamus. 


\section{Sumário}

1 Introdução

2 Direitos Humanos e Direitos Fundamentais 16

2.1. A dignidade da pessoa humana

2.2. A fundamentação dos direitos humanos e dos direitos fundamentais 21

2.3. O Direito Positivo como realização dos Direitos Fundamentais 26

2.4. A crise do Positivismo e a supressão dos Direitos Fundamentais 29

2.4.1. A separação entre direito e moral 29

2.4.2. O Final da segunda guerra mundial e a busca pelo fundamento ético do direito

2.5. O conteúdo axiológico das normas de direitos humanos como proteção contra o positivismo legalista

2.5.1. Direitos humanos, valores e princípios jurídicos 40

2.5.2. Valor e constituição $\quad 47$

2.5.3. Os direitos fundamentais e o modelo de regras e princípios $\quad 49$

2.6. A proteção internacional dos direitos humanos 54

2.7. Direitos fundamentais na Constituição da República Federativa do Brasil

2.7.1. A complementaridade entre a proteção internacional e a proteção local dos direitos humanos

3 A internalização dos tratados internacionais de direitos humanos no direito brasileiro

3.1. Fontes do direito internacional 72

3.1.1. O costume 73

3.1.2. Os princípios gerais de direito 75

3.1.3. Decisões judiciais e doutrina 78

3.2. Os tratados internacionais 79

3.2.1. Elementos dos tratados internacionais 84

3.2.2. Condições de validade dos tratados internacionais 89 
3.2.3. A conclusão dos tratados internacionais e sua obrigatoriedade para os estados celebrantes.

$\begin{array}{ll}\text { 3.2.3.1. A assinatura } & 100\end{array}$

$\begin{array}{ll}\text { 3.2.3.2. A ratificação } & 101\end{array}$

3.2.3.2.1. A competência do Poder Executivo para celebrar tratados 103

3.2.3.2.2. O controle do procedimento de celebração de tratados pelo

Poder Legislativo

3.2.3.2.3. A ratificação como competência discricionária do poder executivo

3.2.3.3. Registro e publicação dos tratados

3.3. A internalização dos tratados internacionais 116

3.3.1. As relações entre o direito internacional e o direito interno 117

3.3.1.1. O Dualismo 118

$\begin{array}{ll}\text { 3.3.1.2. Monismo } & 120\end{array}$

3.3.1.3. As críticas ao dualismo e ao monismo: As teorias conciliadoras

3.3.1.4.Dualismo e monismo; $\quad$ teorias distintas para problemas diferentes

3.4. O problema da internalização dos tratados internacionais no direito comparado.

3.5. A internalização dos tratados internacionais no direito brasileiro 135

3.5.1. Da obrigatoriedade do ato de internalização 142

3.5.2. A hierarquia das normas convencionais internalizadas $\quad 149$

3.5.3. Os tratados internacionais de direitos humanos 153

3.5.4. A internalização dos tratados internacionais de direitos humanos pelo Brasil

3.5.5. O Supremo Tribunal Federal e a internalização dos tratados internacionais de direitos humanos

4 A internalização dos tratados internacionais de direitos humanos como lei de conteúdo constitucional 163

4.1. A dignidade da pessoa humana e o princípio democrático 164

4.1.1. A participação política como aspecto social do princípio da 
dignidade da pessoa humana

4.2. Constituição, legitimidade e a necessidade do ato de internalização da norma convencional de direitos humanos

4.2.1. Os tratados internacionais como leis formais e a obrigatoriedade de sua promulgação

4.2.2. A possibilidade de ponderação do princípio da dignidade humana

4.3. O conteúdo constitucional das normas convencionais internacionais de direitos humanos

4.3.1. O jus cogens internacional e a internalização dos tratados internacionais de direitos humanos

4.3.2. Normas constitucionais inconstitucionais e normas convencionais constitucionais - O problema dos "não direito fundamentais" e dos direitos fundamentais extraconstitucionais

4.4. O Problema da identificação das normas internacionais de direitos humanos

4.4.1. Universalismo versus particularismos regionais.

4.4.2. Democracia, procedimento legislativo e identificação das normas de direito fundamental

4.4.3. O problema da identificação dos tratados internacionais de direitos humanos

5 A Constituição da República e a omissão do Estado brasileiro em internalizar as normas convencionais internacionais de direitos humanos

5.1. O esgotamento dos recursos internos como requisito para a obtenção da proteção internacional dos direitos humanos

5.2. A proteção judicial conferida pela Constituição da República em face da omissão do Estado em internalizar os tratados internacionais de direitos humanos, ratificados pelo Brasil, que estejam em vigor 221

5.2.1. A responsabilidade civil do Estado brasileiro por omissão de ato legislativo

5.2.2. Do cabimento do mandado de injunção para suprir a omissão do Brasil internalizar os tratados internacionais. 
5.2.3. O mandado de segurança como instrumento constitucional destinado a assegurar a incorporação da norma de direito internacional de direitos humanos.

236

6 Conclusão

244

7 Bibliografia

248 